\title{
Cytomegalovirus Hepatitis in Immunocompetent and Immunocompromised Hosts
}

\author{
Teresa Da Cunha*10 and George Y. Wu1,20 \\ ${ }^{1}$ Department of Medicine, Division of Gastroenterology-Hepatology, University of Connecticut Health Center, Farmington, \\ CT, USA; ${ }^{2}$ Current address: Department of Medicine, University of Connecticut Health Center, Farmington, CT, USA
}

\begin{abstract}
Human cytomegalovirus (HCMV) infection is common and affects between $40-100 \%$ of the worldwide population. However, the majority of cases are asymptomatic and when severe disease occurs, it is usually restricted to immunocompromised patients. Liver involvement by HCMV differs significantly, accordingly to the immune status of the host. In immunocompromised patients, particularly liver transplant patients, it often causes clinically significant hepatitis. On the other hand, in immunocompetent patients, HCMV hepatitis requiring hospitalization is extremely rare. This review aims to appraise studies regarding the pathophysiology of HCMV hepatitis, including mechanisms of latency and reactivation and its contribution to disease development, clinical presentation, diagnostic modalities and treatment, with a focus on comparing different aspects between immunocompromised and immunocompetent hosts.
\end{abstract}

Citation of this article: Da Cunha T, Wu GY. Cytomegalovirus hepatitis in immunocompetent and immunocompromised hosts. J Clin Transl Hepatol 2021;000(000):000-000. doi: $10.14218 /$ JCTH.2020.00088.

\section{Introduction}

Human cytomegalovirus (HCMV) is a common pathogen, thought to affect $40 \%$ to $100 \%$ of the world population. ${ }^{1}$ It is mainly transmitted through close contact by body fluids, such as saliva, blood, urine, breast milk, semen and cervical secretions, and also by organ transplantation. It can infect a vast number of cells within the host, including epithelial cells, endothelial cells, parenchymal cells, connective tissue cells and several types of hematopoietic cells. This facilitates both inter-host transmission and systemic transmission within the host. ${ }^{2}$

The clinical manifestations are extensive and vary particularly between immunocompetent and immunocompromised hosts. While the vast majority of immunocompetent

Keywords: CMV hepatitis; Cytomegalovirus hepatitis; Cytomegalovirus hepatitis immunocompetent; Cytomegalovirus hepatitis immunocompromised. Abbreviations: D+/-, donor positive/negative; EBV, Epstein-Barr virus; LSEC, liver sinusoidal endothelial cell; HCMV, human cytomegalovirus; HLA, human leukocyte antigen; HSCT, hematopoietic stem cell transplantation; MHC, major histocompatibility complex; $\mathrm{PCR}$, polymerase chain reaction; $\mathrm{R}+/-$, recipient positive/negative.

Received: 15 September 2020; Revised: 22 November 2020; Accepted: 08 December 2020

${ }^{*}$ Correspondence to: Teresa Da Cunha, Department of Medicine, University of Connecticut Health Center, Farmington, CT 06030, USA. Tel: 860-706-2133; Fax: 860-679-3159; E-mail: dacunha@uchc.edu hosts have a completely asymptomatic course, the immunocompromised host may experience a wide range of severe complications, including esophagitis, colitis, hepatitis, encephalitis, pneumonitis, bacterial superinfection. ${ }^{1}$ In addition, acute infection, chronic infection and reactivation of the virus generate different clinical identities.

In immunocompetent hosts, clinically significant hepatitis is rare and only case reports or small case series are available in the literature. Its presentation is usually a spectrum of malaise and fever, without the classical jaundice seen with the common hepatitis viruses. ${ }^{3}$ Other cases have reported an asymptomatic course or association with abdominal pain only. However, hepatitis is a well-known manifestation of HCMV infection in immunocompromised hosts, particularly in liver transplant patients, in which the incidence is relatively high. Indeed, fulminant hepatitis requiring living-donor liver transplant has been described in this population. 4

Like other herpes viruses, HCMV has the ability to create a lifelong latent infection. Through a variety of complex mechanisms, HCMV modulates the host cell cycle to create an optimal environment for continuous and efficient replication. 5 This lifecycle characteristic allows for viral reactivation and consequently HCMV-related acute disease, including acute hepatitis.

The exact mechanisms by which HCMV induces hepatitis are not well established. However, the role of the immune system appears to be important as an indirect cause of liver damage. Because of the overall rarity of the disease, especially in immunocompetent patients, delay in diagnosis is common, resulting in unnecessary and expensive diagnostic testing. Furthermore, delays can lead to incorrect management and poor outcomes.

The aim of this manuscript is to review the pathogenesis, presentation, diagnosis and management of HCMV hepatitis, with a focus on host immune status.

\section{Epidemiology}

The overall seroprevalence of HCMV has been estimated to range from $45 \%$ to $100 \% .{ }^{1}$ This large number is related to the high number of asymptomatic individuals who do not seek medical care. In addition, several risk factors contribute to changes in seropositivity rate across various groups. According to the National Health and Nutrition Examination Surveys from 1988-2004, which analyzed the HCMV seroprevalence in the USA, HCMV prevalence was associated with increasing age and was slightly higher in women, nonHispanic black ethnicity, and Mexican Americans. Furthermore, foreign birthplace, lack of insurance, and low income and low education households were also associated with a higher infection rates. ${ }^{6}$

Symptomatic HCMV infection is rare in immunocompe- 
Da Cunha T. et al: Cytomegalovirus hepatitis

tent hosts. When present, it usually manifests as a mononucleosis-like syndrome in approximately $10 \%$ of patients. ${ }^{7}$ The estimated incidence of mononucleosis-like syndrome secondary to HCMV infection in hospitalized immunocompetent patients in Hong Kong was reported to be 9.54 per million patient discharges in 2005-2007, and 19.52 per million patient discharges for the period of 2014-2016. ${ }^{7}$

Even though liver dysfunction is not uncommonly associated with HCMV mononucleosis in immunocompetent hosts, there are only case reports of clinically significant HCMV hepatitis available in the literature. To date, there have been 26 descriptions of either case reports or case series of HCMV hepatitis in a total of 44 immunocompetent hosts.

On the other hand, clinically significant HCMV hepatitis is more frequent in the immunocompromised population, particularly in liver transplant patients. For instance, Seehofer et al. ${ }^{8}$ observed a $2.1 \%$ rate of HCMV hepatitis in 1,146 consecutive liver transplantations. In terms of incidence of viremia, in a study of 182 liver transplant patients to whom pre-emptive therapy was used but no antiviral prophylaxis was employed, Singh et al., ${ }^{9}$ observed a HCMV infection rate of $32.5 \%$ ( 38 of 117 ) of recipient positive $(R+)$ patients, $84.6 \%$ (33 of 39 ) of donor positive $(D+) /$ recipient negative $(R-)$, and $3.8 \%(1$ of 26 ) of donor negative (D-)/ $\mathrm{R}-$ patients.

\section{Pathogenesis of HCMV}

\section{Systemic viral dissemination}

The HCMV possesses glycoproteins that can interact with a vast number of different cell surfaces within the human body and initiate its life cycle. ${ }^{10}$ This unique characteristic allows for a broad cellular tropism. The hematogenous spread of the virus allows for its systemic dissemination. ${ }^{11}$ Recent observations have shown that polymorphonuclear leukocytes can more efficiently carry and disseminate the virus. ${ }^{11,12}$ Nonetheless, Sinzger et al. ${ }^{13}$ also observed infected macrophages in the lung and gastrointestinal tissues. Later studies supported this by suggesting that monocytes carry a comparable amount of viral load, thus contributing to systemic viral dissemination. ${ }^{14}$ Once successful termination of acute infection is achieved, a period of latency/persistence is initiated, during which multiple episodes of viral reactivation and transmission can occur.

\section{HCMV infection of hepatic cells}

Theise et al. ${ }^{15}$ studied liver biopsies from seven patients with HCMV hepatitis and detected that the infection started in the cells lining the sinusoids (including Kupffer and endothelial cells), proposing that hematogenous spread to the liver occurs first. Furthermore, hepatocytes were noted to be infrequently infected. On the contrary, Sano et al. ${ }^{16}$ found that hepatocytes were the most frequently infected cell line, and bile duct involvement was only identified in one case. ${ }^{16}$ However, they did not provide evidence of infection in Kupffer cells or other sinusoidal cells. Sinzger et al. ${ }^{17}$ studied HCMV infection in cultured human liver cells. They detected viral antigens from all phases of viral replication, suggesting that the tissue allowed for complete viral replication. In this study, various target cells were identified by immunocytochemical double-labelling, including bile duct cells, fibroblasts, and hepatocytes. They observed that hepatocytes were the primary cell target and supported the late stages of viral replication, indicating that this cell line participates in production of progeny virus. Olver et al.18 also found that hepatocytes were the predominant cell target in HCMV hepatitis in their mice studies.

\section{Indirect vs. direct cytopathogenicity of HCMV in the liver}

It has been reported that the HCMV exhibits both direct and indirect cytopathogenicity in various organs, including the liver. It is believed that liver dysfunction occurs primarily from indirect cytopathogenicity of cytotoxic T-lymphocyte (CD8+) lineage. Pape et al. ${ }^{19}$ identified accumulations of cytolytic $\mathrm{T}$ lymphocytes in the areas of liver tissue injury caused by HCMV, by means of monoclonal antibodies. This provided evidence of indirect pathogenicity by immune-related cytotoxicity and cytokine damage from the host immune system defense against the virus. Several hypotheses have emerged to explain the mechanism of tissue damage through indirect cytopathogenicity, including activation of cytotoxic $T$ cell reactions against HCMV-infected cells, ${ }^{2,20,21}$ vasculitic alterations and subsequent localized necrosis, 22 and in relation to allograft transplantation. 2,20-22 In the latter, the purposed mechanism comprises a possible enhancement in the frequency of lymphocytic activation or increased MHC expression, which further exacerbated the immunological detrimental effects. 2,20

Sinzger et al. ${ }^{13}$ observed lysis of cultured liver cells infected with HCMV, supporting the role of the virus in direct cytopathogenicity. They concluded that HCMV can cause direct liver parenchyma damage through cytolytic mechanisms. However, despite the fact that the virus can be present in hepatocytes and bile ducts, its presence in the majority of cases has been shown to be moderate and not correlated to the degree of liver dysfunction. ${ }^{2,23}$

Livingston-Rosanoff et al. ${ }^{24}$ compared the immunological aspects involved in HCMV hepatitis in both immunocompetent and immunocompromised mice to better understand the extent of indirect cytopathogenicity caused by this virus. In their study, they injected a highly virulent strain of murine HCMV to each of the mice groups and observed that the immunocompetent group developed faster lethal hepatitis than the other. This could be related to a combination of high immune response and direct viral cytotoxic activity (given the highly lethal viral strain). They also concluded that not only CD8+ T cells but also CD4+ T cells might play an important role by producing several cytokines (i.e. IL17, IFN- $\gamma$, and TNF) that contribute to the further enhancement of the host adaptive immune response. From another perspective, other mouse studies demonstrated the critical importance in the role of T lymphocytes in murine cytomegalovirus. Stahl et al. ${ }^{25}$ demonstrated that liver damage and consequent release of liver enzymes in immunocompetent mice occurred earlier than in immunocompromised. This observation can be explained by the early immune response that mainly involves T lymphocytes and natural killer cells and contributes to early tissue damage. However, there was a decrease in liver enzymes at day 6 after infection, which reflects the host immune control over the virus. In contrast, in immunocompromised mice, the elevation of liver enzymes was observed later and lasted longer. Consequently, the liver damage in this host occurred later and was attributed to direct cytopathic effect caused by the virus.

Liver involvement by the HCMV has been reported as hepatitis alone, granulomatous hepatitis, necrotizing hepatitis, and hepatic dysfunction associated with portal vein thrombosis. As mentioned before, although direct cytopathogenicity does play a role in these identities, the inflammatory response with continuous cytokine release appears to be the predominant hepatopathic mechanism, especially in immunocompetent patients. Thus, there is an important 
Da Cunha T. et al: Cytomegalovirus hepatitis

balance between the protective effects and extent of tissue damage caused by a natural host immune response.

\section{Mechanism of HCMV latency and reactivation}

\section{Latency}

During HCMV infection in the liver, liver sinusoidal endothelial cells (LSECs) do not function as a barrier to the virus. Rather, they allow for dissemination to the rest of the liver. ${ }^{26}$ Seckert and colleagues ${ }^{27}$ studied the function of these cells in mice when exposed to HCMV. They observed that LSECs were sites for murine HCMV latency and potential reactivation. However, the same was not observed in hepatocytes. ${ }^{17}$

Other functions of LSECs have been hypothesized. Namely, their role in modulating $T$ cell recruitment and activation, and thus in promoting immune activation in the liver. Specifically, it has been shown that these cells facilitate the transendothelial migration of ICAM-1 and CXCL10-dependent CD4+ T cells. Furthermore, in that study, recruited T cells were primarily non-virus-specific effector memory $T$ cells and activated regulatory $T$ cells with a suppressive phenotype. Thus, this cell type contributes to viral persistence. 28

Hepatocytes play a major role in viral production and dissemination, but do not directly contribute to viral latency. On the contrary, LSECs have a very small capacity to allow viral reproduction and for this reason are less susceptible for direct viral cytopathogenicity and function as an optimal environment for viral latency.

\section{Reactivation}

HCMV is able to escape both innate and adaptive immunity. Several genes have the ability to down-regulate major histocompatibility complex (MHC) class I and MHC class II and may be involved in inhibition of antigen presentation. 23

Furthermore, HCMV can activate or down-regulate receptors found on natural killer cells, natural killer T cells, and $\mathrm{T}$ cells. ${ }^{2}$ Several factors can influence reactivation of the virus, including immune cell depletion, allogenic transplantation, ischemia/reperfusion injury, sepsis, and other inflammatory states. 29

Although HCMV reactivation results in systemic viremia, subsequent hepatitis as a result of viral reactivation has not been clearly reported in immunocompetent patients. However, in liver recipient patients, HCMV reactivation can cause hepatitis, but at a much lower risk compared to primary infection. ${ }^{30}$ From among 93 liver transplant cases, Paya et al. ${ }^{30}$ reported that 19 of the cases developed HCMV infection. However, from the group of HCMV-seronegative-donor/HCMV-seropositive-recipients, only one developed hepatitis. Patients undergoing liver transplant are at increased risk of HCMV reactivation, particularly if receiving antilymphocyte preparations, which are highly potent reactivators of HCMV. On the other hand, immunosuppressors such as cyclosporine and corticosteroids do not cause reactivation but can contribute to increased viral replication. $30-32$

Reactivation of the virus in liver transplant can be both the cause and the consequence of allograft rejection. ${ }^{32} \mathrm{Ra}-$ zonable et al. ${ }^{33}$ studied the clinical predictors of late-onset HCMV disease in liver and kidney transplant recipients who received oral ganciclovir prophylaxis. They observed that allograft rejection was a significant risk factor for occurrence of HCMV disease, including hepatitis. Furthermore, its incidence was higher among liver transplant recipients. This might be explained by the release of multiple cytokines, particularly TNF-a, which has been shown to induce HCMV reactivation. 34,35 On the other hand, immunosuppressive therapy inhibits viral cell-mediated immunity, allowing increased viral replication rates. ${ }^{36}$

\section{Clinical presentation}

The clinical presentation of HCMV infection varies among immunocompetent and immunocompromised hosts, as well as between acute and chronic stages. The spectrum is wide and can range from an asymptomatic infection to life-threatening. Nonetheless, the majority of patients, both immunocompetent and immunocompromised, undergo an asymptomatic disease course from the acute phase until the persistent and latent phases. The main at-risk immunocompromised hosts are fetuses, allograft recipients (due to cytotoxic anti-rejection agents), and human immunodeficiency virus infection. In these hosts, severe end-organ dysfunction can occur, such as hepatitis, retinitis, thrombocytopenia, and neurologic disease. ${ }^{37,38}$

\section{Immunocompetent patients}

Immunocompetent hosts with HCMV infection may experience a mononucleosis-like syndrome with fevers, malaise, presence of lymphocytosis with atypical lymphocytes, occasionally a rash, and abdominal pain. Furthermore, associated hepatic dysfunction and splenomegaly are common. In contrast with Epstein-Barr virus (commonly known as EBV), this presentation usually does not involve tonsillitis and cervical lymphadenopathy, and there is no detectable heterophile antibody. 39

Given the overall rarity, only case reports or small case series of HCMV-induced hepatitis in immunocompetent patients have been published. We found 26 studies reporting HCMV-induced hepatitis in immunocompetent hosts, comprising a total of 44 patients. A total of $34(77 \%)$ patients either had fever at home or upon presentation or malaise $(n=13)$ and abdominal pain $(n=10)$. On exam, only 10 (23\%) patients had jaundice. Similarly, lymphadenopathy was only present in $10(23 \%)$ patients, while $5(11 \%)$ patients presented with a non-specific rash. Furthermore, 22 $(50 \%)$ of the patients had either splenomegaly and/or hepatomegaly. Table 1 summarizes the clinical presentation of immunocompetent patients with HCMV hepatitis. 3,4,40-62

\section{Immunocompromised (liver transplant patients)}

The main groups of adult immunocompromised hosts susceptible to HCMV disease include allograft recipients and patients with human immunodeficiency virus infection with loss of CD4+ lymphocytes. More recently, the use of antiTNF therapy has also resulted in severe HCMV disease with end-organ dysfunction. ${ }^{63}$ Amongst the different types of immunocompromised hosts, there is a common viral syndrome with fever and malaise and possibly elevated liver enzymes. Studies on significant HCMV-induced hepatitis in the immunocompromised population have only been well described in liver transplant patients.

Liver transplant patients had a reported high incidence of HCMV infection which led to a viral syndrome with fever, malaise and some degree of bone marrow suppression, or tissue invasive disease. The latter mainly affects the gastrointestinal tract (i.e. gastritis, esophagitis, enteritis, and/ or colitis) and with a relatively high incidence, the liver, and consequently hepatitis. 8,30,64 An important aspect that is regarded as a risk factor for HCMV disease in liver transplanta- 
Da Cunha T. et al: Cytomegalovirus hepatitis

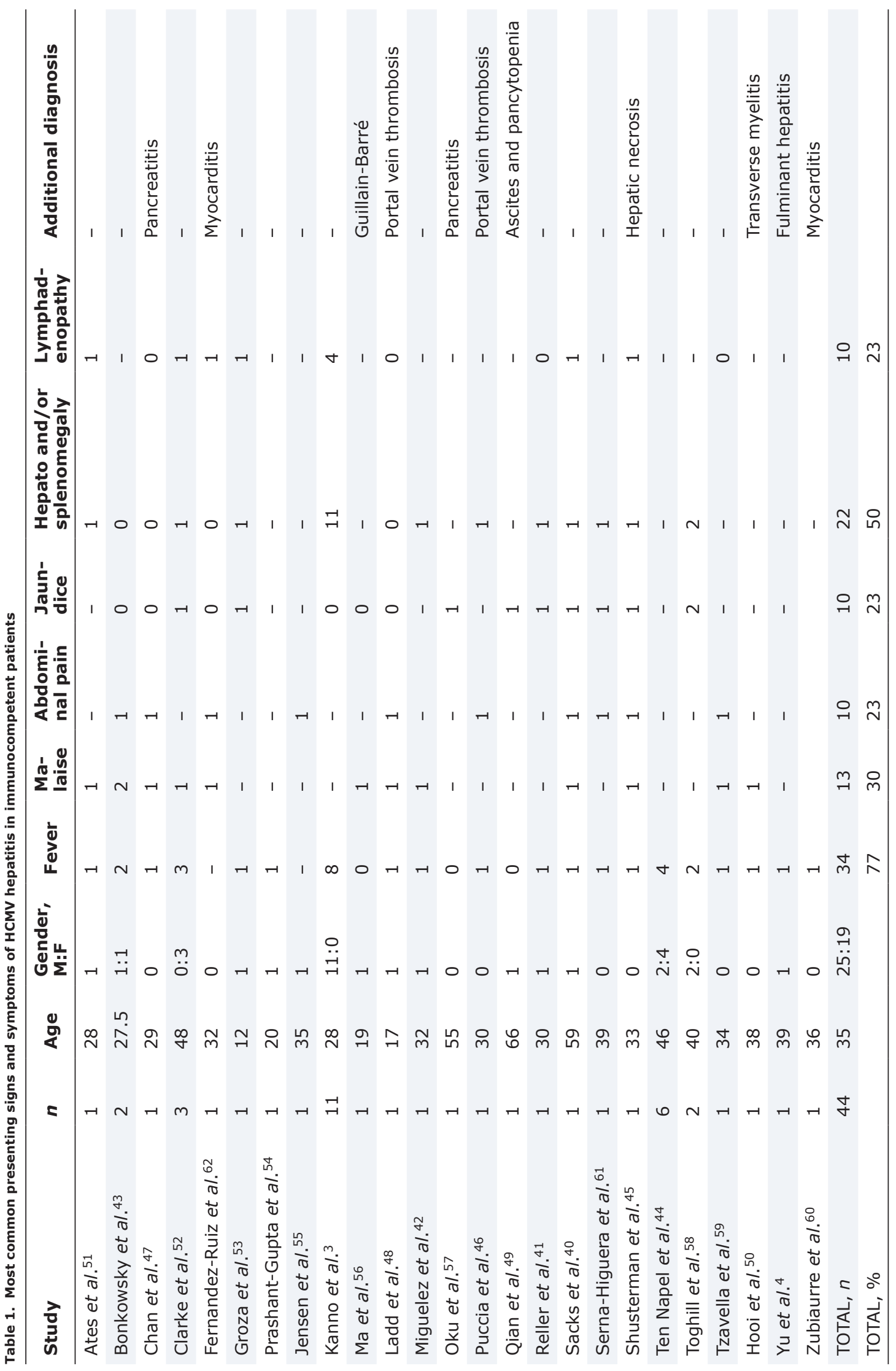


tion is the serological status of both the donor and recipient. HCMV-seropositive-donor/HCMV-seronegative-recipient are at increased risk of HCMV hepatitis, whereas HCMV-seropositive-recipients have a moderate risk and HCMV-seronegative-donor/HCMV-seronegative-recipients have a lower risk. ${ }^{30}$ Paya et al. ${ }^{30}$ reported an incidence of $17 \%$ of acute hepatitis following 93 liver transplantations. However, Seehofer et al. ${ }^{8}$ evaluated 1,200 liver transplant patients and of these only $2.1 \%$ developed acute hepatitis. This difference could be due to not only the difference in sample size but also to dissimilarity in immunosuppressive therapy after transplantation. For this reason, a precise number is difficult to obtain. In both studies, the incidence of acute HCMV hepatitis was higher in seronegative recipients compared to seropositive recipients. Paya et al. ${ }^{30}$ found that HCMV hepatitis was most common in liver transplantation for cholestatic disease (i.e. primary biliary cirrhosis and primary sclerosing cholangitis). Unfortunately, that study did not clearly describe the number of patients for each specific etiology requiring a liver transplant. In that same study, HCMV hepatitis was more frequent in patients who required retransplantation (38\%) than in those who received one hepatic allograft (12\%).8,30

As in immunocompetent patients, patients commonly had a mononucleosis-like syndrome including fever and malaise. $31,65,66$ In both studies discussed above, fever occurred in $24 \%$ and $84 \%$ of the patients. 8,30 Furthermore, Paya et al. ${ }^{30}$ described myalgia in $31 \%$ of patients. Extrahepatic involvement was somewhat infrequent in the two studies, pneumonitis occurred in four patients (three in Paya et al. ${ }^{30}$ and one Seehoffer et $a l^{8}$ ) and generalized organ involvement in one patient.

It has been noted that HLA-donor/recipient matches were significantly higher in patients that developed HCMV hepatitis. ${ }^{67}$ Moreover, HCMV hepatitis was reported in a patient with Crohn's disease who was previously on mercaptopurine and switched to infliximab 1 year prior to presentation.63 This case shows that the role of TNF-a in HCMV infection is complex. As previously mentioned, it has been associated with induction of HCMV reactivation in allograft rejection. ${ }^{34,35,68}$ However, a signaling cascade is also important in inducing an antiviral state. ${ }^{69,70}$

\section{Role of HCMV in chronic liver disease}

To understand whether HCMV infection could play a role in unexplained cases of chronic liver disease, Toghill et al. ${ }^{71}$ analyzed 70 patients with cirrhosis with the following diagnosis: alcoholic cirrhosis, cryptogenic cirrhosis, primary biliary cirrhosis, hemochromatosis, drug-induced jaundice, secondary biliary cirrhosis, and congenital hepatic fibrosis. They did not find any evidence for HCMV as the cause of liver disease. There was no significant difference in the antibody titers of these patients compared to that of the general population.

On the contrary, HCMV infection in post-liver transplant patients has been associated with chronic rejection. ${ }^{72,73}$ The main suggested cause of chronic rejection is the vanishing bile duct syndrome. Lautenschlager et al. ${ }^{72}$ investigated the relationship between HCMV and chronic liver rejection with vanishing bile duct syndrome in 10 patients and verified that all the patients had persistence of HCMV genome in the graft. Furthermore, HCMV reactivation was associated with late acute rejections. Moreover, Faivre et al. ${ }^{74}$ verified that HCMV was associated with an increased risk of liver-related death in patients with liver cirrhosis.

Although HCMV infection has not been directly seen as the cause of liver cirrhosis, there appears to be evidence in support of a higher mortality in these patients. In addition, it is an important cause of chronic liver rejection in transplant patients.

\section{Diagnosis}

The diagnosis of HCMV hepatitis requires liver tissue biopsy for confirmation of HCMV presence in the liver. The best modality for identification of viral inclusions or viral antigens is immunohistochemistry. ${ }^{75}$ However, detection of HCMV by means of acute serology or polymerase chain reaction (PCR) can provide faster results when the suspicion of HCMV-induced hepatitis is high, allowing for an earlier management plan when biopsy results are pending. In many circumstances, particularly in immunocompetent patients who present with acute elevation of liver enzymes, acute HCMV serology may be sufficient for diagnosis of HCMVinduced hepatitis when other causes have been ruled out. Furthermore, it can be used to monitor disease progression and treatment response in combination with liver function results.

\section{Liver enzyme tests}

Elevation of hepatic aminotransferases in HCMV infection is non-specific but levels are on average lower than those seen in hepatitis caused by hepatitis viruses. ${ }^{3}$ In immunocompromised patients, 1.3 -fold elevations in mean alanine aminotransferase has been reported. ${ }^{8}$ Paya et al. ${ }^{30}$ observed 2-30 times higher (mean 9.3-fold above upper limits of normal) levels of gamma-glutamyltransferase and 1-10 times higher (mean 3.6) in alkaline phosphatase levels compared to aminotransferases. Furthermore, the elevation of gamma-glutamyltransferase and alkaline phosphatase may persist longer than that of alanine aminotransferase and aspartate aminotransferase. 8,30 The levels of bilirubin elevation in this study were relatively low, 1-4 times higher than the normal levels.

From the analysis of independently reported cases of HCMV hepatitis in immunocompetent patients, the mean aspartate aminotransferase was $422( \pm 582), n=38$, and the mean alanine aminotransferase $521( \pm 579), n=37$. The mean total bilirubin value was $5 \mathrm{mg} / \mathrm{dL}( \pm 9), n=33$. Overall, there was a higher elevation of aminotransferases in immunocompetent patients compared to immunocompromised. This observation could be related to the early and robust immune response in immunocompetent patients, and the consequent indirect cytopathogenicity. These immunocompromised patients underwent liver transplantation and were closely monitored for HCMV hepatitis, resulting in earlier diagnosis and subsequent treatment with ganciclovir. Bilirubin elevation was minimal in both population groups.

\section{Serology}

While serology in the immunocompetent patient plays an important role in the diagnosis of HCMV hepatitis, it has a limited role in the immunocompromised because of an immune system impairment in mounting an antibody response. ${ }^{76}$ However, serological testing can provide a good assessment of recipient risk prior to transplant. ${ }^{31,77}$ In immunocompetent patients, it provides a fast, non-invasive and less expensive test when used in the context of hepatitis and when other etiologies have been ruled out. However, IgM antibody assays may be falsely positive due to persistence of high IgM levels long after primary infection. It can also represent viral reactivation. ${ }^{78}$ Furthermore, HCMV IgM might be falsely positive in the presence of a positive rheumatoid factor or with infection of other herpes virus. ${ }^{79}$

The sensitivity and specificity of serology have been reported between $70.7-84.4 \%$ and $99.3-100 \%$, respec- 
tively. ${ }^{80,81}$ Another study that compared five different commercial immunoassays for the serologic diagnosis of HCMV showed significant differences in sensitivity and specificity between the different tests as well as in cross reactions with EBV-IgM and rheumatoid factor. ${ }^{82}$

\section{Antigenemia}

The pp65 HCMV antigenemia assay detects HCMV antigens in peripheral blood leukocytes. ${ }^{39,83}$ It has a good utility for monitoring disease progression and treatment response. However, given its limitation of detecting the virus only in leukocytes, it may not be reliable in patients with leukopenia, ${ }^{78}$ as this may contribute to false negative results. Its sensitivity and specificity have been reported as $64 \%$ and $81 \%$, respectively. 84

\section{Culture}

The utility of viral culture is limited because of the long time required for results. ${ }^{85}$ In 65 patients with HCMV hepatitis, Brand et al. ${ }^{85}$ were able to confirm the diagnosis in $63 \mathrm{pa-}$ tients through histology and early antigenemia, but viral culture only contributed to the management of 1 patient among 2,508 liver biopsies. A study comparing several diagnostic techniques for HCMV detection in liver transplant patients using 108 hepatic tissue specimens also showed an overall low sensitivity (52\%) of cell culture for detecting the virus. ${ }^{86}$ However, the use of shell vial assay provided results within $12 \mathrm{~h}$ and not only had a similar specificity to traditional culture but also higher sensitivity. ${ }^{87}$

\section{PCR}

PCR can identify HCMV from body fluid or tissue. Furthermore, it can provide both qualitative and quantitative measurements. Quantitative PCR is generally used in immunocompromised patients to determine which patients need preemptive therapy and for monitoring disease response. ${ }^{78,88}$ Methods using real-time PCR have better precision, are easier to perform, faster and less risk of contamination compared to conventional PCR. ${ }^{89,90}$ It is a reliable, sensitive and very specific method, with sensitivities ranging from $61-92 \%$ and specificities $75-99 \% .91,92$

\section{Histopathological findings}

The most consistent finding of HCMV hepatitis in liver biopsies of both immunocompetent and immunocompromised patients is a mononuclear infiltrate. $3,40-43,86,93,94$ However, the degree of inflammatory infiltrate differs. Immunocompromised patients have an overall low degree of inflammatory mononuclear infiltrate. For instance, Sano et al. ${ }^{16}$ studied immunocompromised patients with underlying malignancy, and from three liver biopsies with detected HCMV, there was hardly any inflammatory infiltrate around the infected cells. Similar findings were observed in two patients after renal transplantation and one patient with Hodgkin's disease. ${ }^{44}$

Ten patients assessed by Ten Napel et al. ${ }^{44}$ showed relative similarities to inflammation and viral expression in portal and periportal regions between both immunocompetent and immunocompromised. On the other hand, the immunocompetent patients had a higher level of mononuclear infiltrate in the liver parenchyma. However, the magnitude of hepatocyte damage was lower compared to that in immunocompromised patients. Although focal necrosis is more common in the immunocompromised population, there is one isolated report of fatal hepatitis in a previously healthy patient for whom liver biopsy had showed broad bands of necrosis. ${ }^{45}$

Lautenschlager et al. ${ }^{79}$ reviewed biopsies of 26 livers from patients who had a liver transplant and subsequent HCMV liver infection. The most common observation was the presence of micro-abscesses, which have been described before. ${ }^{15}$ Another finding that has been more frequently seen in immunocompetent patients are granulomas. In addition, these are more commonly seen in HCMV hepatitis in contrast to other viral causes of hepatitis. 3,41,43

The degree of the host immunodeficiency likely affects the extension of the inflammatory reaction observed in the specimens. As discussed above, lack of immune response might allow an increased direct viral cytopathogenicity, which leads to more extensive necrosis. Despite an overall lower magnitude of inflammatory infiltrate observed in the liver of these patients, the presence of either HCMV inclusion bodies or the detection of HCMV antigens confirms the diagnosis. Table 2 describes, in more detail, the biopsy findings of 22 previously healthy immunocompetent patie nts. $40-45,47,52,53,58,61$ Table 3 summarizes the main biopsy findings of immunocompetent and immunocompromised patients.

\section{Treatment}

The recommendations for antiviral initiation in HCMV hepatitis differ according to the patient population. As a result of a high incidence of HCMV hepatitis in patients undergoing liver transplantation, the main approach of management relies on preventing disease occurrence. ${ }^{32}$ There are two approaches in prevention, prophylaxis and preemptive therapy. In prophylaxis, antivirals are started just after transplantation occurs and last for at least 3 months. In preemptive therapy, the recipients are closely monitored for the presence of HCMV replication before any symptoms occur; if HCMV replication is identified, antiviral treatment is promptly initiated.

Antiviral prophylaxis has been the preferred method for high-risk allograft recipients $(D+/ R-) .32$ Treatment is started within 10 days of transplantation, regardless of the existence of HCMV replication or not. In these patients, acyclovir, valacyclovir, intravenous ganciclovir, and valganciclovir can be used. ${ }^{75}$ In a large study from Paya et al., 95 high-risk allograft patients receiving heart, liver, kidney or pancreas received prophylaxis with either ganciclovir or valganciclovir. The efficacy and safety of these drugs were similar but the incidence of HCMV disease was slightly lower in the valganciclovir group $(17.2 \%$ vs. $18.4 \%)$. In other studies, valganciclovir has demonstrated lower incidence of HCMV disease at 6- and 12-months follow-up. 32,33

Preemptive therapy involves close monitoring for viral replication, followed by initiation of therapy when HCMV is detected. At this time, there is no consensus regarding the threshold of viral load and the start of therapy. A recent meta-analysis involving 2,452 liver transplant recipients demonstrated an incidence of HCMV disease of $10 \%$ in patients receiving prophylaxis versus $7 \%$ in those receiving preemptive therapy. In addition, acute cellular rejection and mortality rates were similar in both groups. Importantly, these results comprised all D/R status. ${ }^{96}$ However, Singh et al. ${ }^{97}$ performed a randomized clinical trial to compare preemptive therapy and antiviral prophylaxis in 205 HCMV-seronegative liver transplant recipients $(R-)$ with seropositive donors $(D+)$. In that study, the incidence of HCMV disease 
Da Cunha T. et al: Cytomegalovirus hepatitis

Table 2. Histopathologic findings of liver biopsies in immunocompetent patients

\begin{tabular}{|c|c|}
\hline Study & Liver biopsy findings \\
\hline \multirow[t]{2}{*}{ Bonkowsky et al. ${ }^{43}$} & $\begin{array}{l}\text { Portal triads infiltrated with lymphocytes, histiocytes, plasma cells, and neutrophils. Lobules with } \\
\text { lymphocytes, monocytes and proliferating reticuloendothelial cells. Granulomata in the lobules. } \\
\text { One large epithelioid granuloma with areas of necrosis. }\end{array}$ \\
\hline & $\begin{array}{l}\text { Normal lobular architecture. Many of the portal triads were enlarged, containing a small to } \\
\text { moderate number of lymphocytes and histiocytes. Proliferation of RE cells and infiltration } \\
\text { of lymphocytes in the sinusoids. Few necrotic hepatocytes. Small, sharply circumscribed } \\
\text { granulomata made of closely packed epithelioid cells and rare lymphocytes. No giant cells. }\end{array}$ \\
\hline Chan et al. ${ }^{47}$ & $\begin{array}{l}\text { Mild to moderate infiltrate of small lymphocytes in the sinusoids and a beaded sinusoidal } \\
\text { infiltrate characteristic of HCMV infection. }\end{array}$ \\
\hline \multirow[t]{3}{*}{ Clarke et al. ${ }^{52}$} & Focal areas of necrosis and many noncaseating epithelioid granulomas and portal triaditis. \\
\hline & Non-caseating epithelioid granulomas, focal liver cell necrosis, portal triaditis. \\
\hline & Prominent sinusoidal lymphocytic infiltrate and early granuloma formation. \\
\hline Groza et al. ${ }^{53}$ & Viral hepatitis in an advanced phase. \\
\hline Miguelez et al. ${ }^{42}$ & Intense mononuclear portal infiltration and severe alteration of zone 3 with confluent necrosis. \\
\hline Reller et al. ${ }^{41}$ & $\begin{array}{l}\text { Non-specific resolving hepatitis with sparce cellular necrosis and mononuclear infiltrates in portal } \\
\text { areas. Scattered granulomas with giant cell formation. }\end{array}$ \\
\hline Sacks et al. 40 & $\begin{array}{l}\text { Acute hepatitis with focal parenchymal necrosis, periportal and sinusoidal mononuclear } \\
\text { infiltration. Focal fatty degenerative changes. }\end{array}$ \\
\hline Serna-Higuera et al. ${ }^{61}$ & $\begin{array}{l}\text { HCMV intranuclear inclusions. Portal spaces with fibrous expansion and irregularly distributed } \\
\text { lymphocytic infiltrate. Fibrin ring granulomas. }\end{array}$ \\
\hline Shusterman et al. ${ }^{45}$ & Hepatic lobules markedly disrupted by broad bands of necrosis. \\
\hline \multirow[t]{5}{*}{ Ten Napel et al. ${ }^{44}$} & $\begin{array}{l}\text { Enlargement of portal tracts, lymphocytic infiltrate, bile duct inflammation, focal necrosis, } \\
\text { granulomas. }\end{array}$ \\
\hline & $\begin{array}{l}\text { Enlargement of portal tracts, lymphocytic infiltrate, lymphocytic spill-over, granulomas, liver } \\
\text { cell degeneration. }\end{array}$ \\
\hline & Enlargement of portal tracts, lymphocytic infiltrate, liver cell degeneration. \\
\hline & $\begin{array}{l}\text { Enlargement of portal tracts, lymphocytic infiltrate, bile duct inflammation, lymphocytic spill- } \\
\text { over, liver cell degeneration. }\end{array}$ \\
\hline & Enlargement of portal tracts, lymphocytic infiltrate, granulomas, focal necrosis. \\
\hline \multirow[t]{2}{*}{ Toghill et al. ${ }^{58}$} & $\begin{array}{l}\text { Areas of liver cell necrosis and mononuclear cell infiltration, acidophil bodies, slight portal } \\
\text { enlargement, siderosis. }\end{array}$ \\
\hline & $\begin{array}{l}\text { Portal and periportal infiltration with chronic inflammatory cells, piecemeal necrosis, fibrosis of } \\
\text { portal areas extending to lobules. }\end{array}$ \\
\hline
\end{tabular}

was significantly lower with pre-emptive therapy ( $9 \%)$ than with anti-viral prophylaxis (19\%). Opposing these results,
Bodro et al. ${ }^{98}$ analyzed $74 \mathrm{D}+/ \mathrm{R}$ - liver recipient patients. Thirty-five patients $(47 \%)$ received prophylaxis, and thirty-

Table 3. Summary of the main histological findings of liver biopsies in immunocompetent and immunocompromised patients

\begin{tabular}{|c|c|c|}
\hline & Immunocompetent & Immunocompromised \\
\hline Portal tracts & $\begin{array}{l}\text { Enlarged portal tracts } \\
\text { Prominent mononuclear portal and } \\
\text { peri-portal infiltrate (frequent) } \\
\text { Reported inflammatory cells: lymphocytes, } \\
\text { histiocytes, plasma cells, neutrophils } \\
\text { Fibrosis of portal areas (rare) }\end{array}$ & $\begin{array}{l}\text { Mild to low mononuclear portal infiltrate } \\
\text { Reported inflammatory cells: mainly lymphocytes }\end{array}$ \\
\hline Parenchyma & $\begin{array}{l}\text { Giant cell granulomas (frequent) } \\
\text { Lymphocytes, monocytes } \\
\text { Sinusoidal lymphocytic infiltrate (frequent) } \\
\text { Few necrotic hepatocytes } \\
\text { Focal areas of necrosis (rare) }\end{array}$ & $\begin{array}{l}\text { Micro-abscesses (frequent) } \\
\text { Giant cell granulomas (very rare) } \\
\text { Parenchymal and sinusoidal inflammatory reaction } \\
\text { Extensive focal liver necrosis }\end{array}$ \\
\hline $\begin{array}{l}\text { Presence of } \\
\text { viral inclusion } \\
\text { bodies }\end{array}$ & Extremely rare & $\begin{array}{l}\text { Moderate (in inflammatory cells of portal } \\
\text { mononuclear infiltrate and in hepatocytes) }\end{array}$ \\
\hline
\end{tabular}


nine patients (53\%) followed a pre-emptive strategy based on CMV antigenemia. They observed an increased rate of HCMV disease in the group that received pre-emptive therapy $(33.3 \%)$ compared to the group that received prophylaxis $(8.6 \%)$. Nonetheless, late-onset HCMV disease was only found in patients receiving prophylaxis $(5.7 \%)$.

Another study from Weigand et al., 99 analyzed 211 liver recipients for the occurrence of CMV infection. From these, $51.7 \%$ received prophylaxis with ganciclovir or valganciclovir. Overall, $32.7 \%$ had CMV infection despite antiviral prophylaxis. It is important to note that antiviral prophylaxis was started in cases of high-risk donor-recipient status, retransplantation, and according to clinical decision. In addition, the authors did not mention if CMV disease occurred.

If HCMV disease (including end-organ damage such as HCMV hepatitis) develops in immunocompromised patients, the main treatment is intravenous ganciclovir or valganciclovir. In addition, immunosuppressive regimens should be reduced as much as possible. The length of treatment varies according to individual response, which can be monitored by clinical and laboratory data.

Importantly, infections by ganciclovir-resistant HCMV has been rising, particularly in patients receiving pre-emptive therapy. In a study with 561 patients who underwent 616 hematopoietic stem cell transplantations (HSCTs), drug resistance was solely observed in haploidentical (haplo)-HSCT recipients receiving pre-emptive therapy and was as high as $14.5 \% .{ }^{100}$ In such patients, treatment is challenging and depends on several factors, including which mutation has led to the viral resistance. ${ }^{101}$ Foscarnet is currently recommended as the first-line option, followed by cidofovir. Of note, both of these drugs have a certain degree of ganciclovir cross-resistance, particularly the latter. ${ }^{83,101}$

The majority of immunocompetent patients with symptomatic HCMV infection had spontaneous resolution of both symptoms and laboratory abnormalities (elevated aminotransferases). ${ }^{46}$ For this reason, there are no specific guidelines for treatment. Furthermore, there are no major studies on antiviral therapy in immunocompetent patients with HCMV disease. Among the 45 immunocompetent patients with HCMV hepatitis that we found in the literature, management with antiviral therapy varied. Only nine cases reported the use of antiviral medications. From these, five received ganciclovir only, two received valganciclovir only, one received ganciclovir followed by foscarnet, and one received ganciclovir followed by valganciclovir. Except for one case, ${ }^{43}$ all other cases that received antiviral therapy comprised patients with additional organ involvement or clinical deterioration; these included pancreatitis, myocarditis, acute pulmonary embolism, encephalopathy, transverse myelitis, pancytopenia, and fulminant hepatitis. 4,42,47-50,61,62 Overall, from among all of the 45 five reported patients with HCMV hepatitis, only 1 died. In this patient, unfortunately, the diagnosis was made just prior to his death and many days after his admission.

Despite the fact that there is no clear indication for treatment of symptomatic HCMV infection in these populations, treatment should be considered when the liver function or overall clinical status of the patient is not improving, or if there is another organ involvement which can be an indicator of disease severity.

\section{Conclusions and recommendations}

Although slightly elevated aminotransferases in the setting of HCMV mononucleosis are common in immunocompetent patients, clinically significant HCMV hepatitis is uncommon, with only few cases reported. In the immunocompromised population, liver transplant patients have an increased risk of HCMV hepatitis.

Hepatocytes play a major role in HCMV replication but do not contribute to viral latency. On the contrary, LSECS have a very low capacity for viral reproduction, and for this reason are less susceptible for direct viral cytopathogenicity and function as an environment for viral latency.

Indirect cytopathogenicity, due to the host immune response, plays a major role in early liver damage, particularly in immunocompetent patients. Furthermore, in this population, hepatitis typically occurs earlier than in immunocompromised patients but also subsides earlier. This is due to the robust immune activation of immunocompetent patients. However, the poor immune response in the immunocompromised patients can lead to a prolonged state of direct cytopathogenicity and, consequently, marked detrimental effects to the liver. Hepatitis as a result of HCMV reactivation has not been reported in immunocompetent patients. In addition, in liver recipient patients, HCMV reactivation can cause hepatitis but at a much lower risk compared to primary infection.

The clinical presentation is non-specific with fever, malaise and/or myalgias being the most common signs/symptoms regardless of immune status. Treatment of HCMV hepatitis with antiviral therapy in the immunocompetent population is not generally recommended but should be considered in patients with severe disease and/or extra-hepatic manifestations. On the other hand, the management approach in immunocompromised patients relies on disease prevention.

\section{Acknowledgments}

The support of the Herman Lopata Chair in Hepatitis Research is gratefully acknowledged.

\section{Funding}

None to declare.

\section{Conflict of interest}

The authors have no conflict of interests related to this publication.

\section{Author contributions}

Wrote and revised the review article (TD), edited the review article (GYW).

\section{References}

[1] Cannon MJ, Schmid DS, Hyde TB. Review of cytomegalovirus seroprevalence and demographic characteristics associated with infection. Rev Med Virol 2010;20:202-213. doi:10.1002/rmv.655.

[2] Sinzger C, Jahn G. Human cytomegalovirus cell tropism and pathogenesis. Intervirology 1996;39:302-319. doi:10.1159/000150502.

[3] Kunno A, Abe M, Yamada M, Murakami K. Clinical and histological features of cytomegalovirus hepatitis in previously healthy adults. Liver 1997;17: 129-132. doi:10.1111/j.1600-0676.1997.tb00794.x

[4] Yu YD, Park GC, Park PJ, Choi YI, Hwang S, Song GW, et al. Cytomegalovirus infection-associated fulminant hepatitis in an immunocompetent adult requiring emergency living-donor liver transplantation: report of a case. requiring emergency living-donor liver transplantation: report of

[5] Spector DH. Human cytomegalovirus riding the cell cycle. Med Microbiol Immunol 2015;204:409-419. doi:10.1007/s00430-015-0396-z.

[6] Bate SL, Dollard SC, Cannon MJ. Cytomegalovirus seroprevalence in the United States: the national health and nutrition examination surveys, 19882004. Clin Infect Dis 2010;50:1439-1447. doi:10.1086/652438.

[7] Sridhar S, Chung TWH, Chan JFW, Cheng VCC, Lau SKP, Yuen KY, et al. Emer- 
gence of cytomegalovirus mononucleosis syndrome among young adults in Hong Kong linked to falling seroprevalence: Results of a 14-year seroepidemiological study. Open Forum Infect Dis 2018;5:ofy262. doi:10.1093/ ofid/ofy 262

[8] Seehofer D, Rayes N, Tullius SG, Schmidt CA, Neumann UP, Radke C, et al. CMV hepatitis after liver transplantation: incidence, clinical course, and long-term follow-up. Liver Transpl 2002;8:1138-1146. doi:10.1053/ jits.2002.36732.

[9] Singh N, Wannstedt C, Keyes L, Wagener MM, Cacciarelli TV. Who among cytomegalovirus-seropositive liver transplant recipients is at risk for cytomegalovirus infection? Liver Transpl 2005;11:700-704. doi:10.1002/It. 20417

[10] Jean Beltran PM, Cristea IM. The life cycle and pathogenesis of human cytomegalovirus infection: lessons from proteomics. Expert Rev Proteomics 2014;11:697-711. doi:10.1586/14789450.2014.971116

[11] Gerna G, Percivalle E, Baldanti F, Sozzani S, Lanzarini P, Genini E, et al. Human cytomegalovirus replicates abortively in polymorphonuclear leukocytes after transfer from infected endothelial cells via transient microfusion events. J Virol 2000;74:5629-5638. doi:10.1128/jvi.74.12.5629-5638. 2000.

[12] Britt W. Manifestations of human cytomegalovirus infection: proposed mechanisms of acute and chronic disease. Curr Top Microbiol Immunol 2008;325: 417-470. doi:10.1007/978-3-540-77349-8_23.

[13] Sinzger C, Plachter B, Grefte A, The TH, Jahn G. Tissue macrophages are infected by human cytomegalovirus in vivo. J Infect Dis 1996;173:240245. doi:10.1093/infdis/173.1.240.

[14] Hassan-Walker AF, Mattes FM, Griffiths PD, Emery VC. Quantity of cytomegalovirus DNA in different leukocyte populations during active infection in vivo and the presence of gB and UL18 transcripts. J Med Virol 2001;64: 283-289. doi:10.1002/jmv.1048.

[15] Theise ND, Conn M, Thung SN. Localization of cytomegalovirus antigens in liver allografts over time. Hum Pathol 1993;24:103-108. doi:10.1016/ 0046-8177(93)90069-s.

[16] Sano N, Izumi K. Hepatic cytomegalovirus involvement in autopsy cases. Acta Pathol Jpn 1991;41:668-672. doi:10.1111/j.1440-1827.1991.tb027 90.x.

[17] Sinzger C, Bissinger AL, Viebahn R, Oettle H, Radke C, Schmidt CA, et al. Hepatocytes are permissive for human cytomegalovirus infection in human liver cell culture and In vivo. J Infect Dis 1999;180:976-986. doi:10.1086/ 315032.

[18] Olver SD, Price P, Shellam GR. Cytomegalovirus hepatitis: characterization of the inflammatory infiltrate in resistant and susceptible mice. Clin Exp Immunol 1994;98:375-381. doi:10.1111/j.1365-2249.1994.tb05500.x.

[19] Pape GR, Rieber EP, Eisenburg J, Hoffmann R, Balch CM, Paumgartner G, et al. Involvement of the cytotoxic/suppressor T-cell subset in liver tissue injury of patients with acute and chronic liver diseases. Gastroenterology injury of patients with

[20] Griffiths PD, Grundy JE. The status of CMV as a human pathogen. Epidemiol Infect 1988;100:1-15. doi:10.1017/s095026880006550x.

[21] Grundy JE, Shanley JD, Griffiths PD. Is cytomegalovirus interstitial pneumonitis in transplant recipients an immunopathological condition? Lancet 1987;2:996-999. doi:10.1016/s0140-6736(87)92560-8.

[22] Kyriazis AP, Mitra SK. Multiple cytomegalovirus-related intestinal perforations in patients with acquired immunodeficiency syndrome. Report of two cases and review of the literature. Arch Pathol Lab Med 1992;116:495499.

[23] Powers C, DeFilippis V, Malouli D, Früh K. Cytomegalovirus immune evasion. Curr Top Microbiol Immunol 2008;325:333-359. doi:10.1007/978-3540-77349-8_19.

[24] Livingston-Rosanoff D, Daley-Bauer LP, Garcia A, McCormick AL, Huang J, Mocarski ES. Antiviral T cell response triggers cytomegalovirus hepatitis in mice. J Virol 2012;86:12879-12890. doi:10.1128/JVI.01752-12.

[25] Stahl FR, Jung R, Jazbutyte V, Ostermann E, Tödter S, Brixel R, et al. Laboratory diagnostics of murine blood for detection of mouse cytomegalovirus (MCMV)-induced hepatitis. Sci Rep 2018;8:14823. doi:10.1038/s41598(MCMV)-induced

[26] Sacher T, Podlech J, Mohr CA, Jordan S, Ruzsics Z, Reddehase MJ, et al. The major virus-producing cell type during murine cytomegalovirus infection, the hepatocyte, is not the source of virus dissemination in the host. Cell Host Microbe 2008;3:263-272. doi:10.1016/j.chom.2008.02.014

[27] Seckert CK, Renzaho A, Tervo HM, Krause C, Deegen P, Kühnapfel B, et al. Liver sinusoidal endothelial cells are a site of murine cytomegalovirus latency and reactivation. J Virol 2009;83:8869-8884. doi:10.1128/JVI.008 70-09.

[28] Bruns T, Zimmermann HW, Pachnio A, Li KK, Trivedi PJ, Reynolds G, et al. CMV infection of human sinusoidal endothelium regulates hepatic $T$ cell recruitment and activation. J Hepatol 2015;63:38-49. doi:10.1016/j. jhep.2015.02.046.

[29] Reddehase MJ, Simon CO, Seckert CK, Lemmermann N, Grzimek NK. Murine model of cytomegalovirus latency and reactivation. Curr Top Microbio Immunol 2008;325:315-331. doi:10.1007/978-3-540-77349-8 18.

[30] Paya CV, Hermans PE, Wiesner RH, Ludwig J, Smith TF, Rakela J, et al. Cytomegalovirus hepatitis in liver transplantation: prospective analysis of 93 consecutive orthotopic liver transplantations. J Infect Dis 1989;160:752758. doi:10.1093/infdis/160.5.752.

[31] Kanj SS, Sharara AI, Clavien PA, Hamilton JD. Cytomegalovirus infection following liver transplantation: review of the literature. Clin Infect Dis 1996;22:537-549. doi:10.1093/clinids/22.3.537.

[32] Bruminhent J, Razonable RR. Management of cytomegalovirus infection and disease in liver transplant recipients. World J Hepatol 2014;6:370383. doi:10.4254/wjh.v6.i6.370.
[33] Razonable RR, Rivero A, Rodriguez A, Wilson J, Daniels J, Jenkins G, et al. Allograft rejection predicts the occurrence of late-onset cytomegalovirus (CMV) disease among CMV-mismatched solid organ transplant patients receiving prophylaxis with oral ganciclovir. J Infect Dis 2001;184:1461-1464. doi:10.1086/324516.

[34] Fietze E, Prösch S, Reinke P, Stein J, Döcke WD, Staffa G, et al. Cytomegalovirus infection in transplant recipients. The role of tumor necrosis factor. Transplantation 1994;58:675-680.

[35] Forte E, Swaminathan S, Schroeder MW, Kim JY, Terhune SS, Hummel M. Tumor necrosis factor alpha induces reactivation of human cytomegalovirus independently of myeloid cell differentiation following posttranscriptional establishment of latency. mBio 2018;9:e01560-e01518. doi:10.1128/mBio. $01560-18$

[36] Hooks MA, Perlino CA, Henderson JM, Millikan WJ Jr, Kutner MH. Prevalence of invasive cytomegalovirus disease with administration of muromonab CD-3 in patients undergoing orthotopic liver transplantation. Ann Pharmacother 1992;26:617-620. doi:10.1177/106002809202600501.

[37] Lamb SG, Stern H. Cytomegalovirus mononucleosis with jaundice as presenting sign. Lancet 1966;2:1003-1006. doi:10.1016/s0140-6736(66) 92929-1.

[38] Fiala M, Heiner DC, Turner JA, Rosenbloom B, Guze LB. Infectious mononucleosis and mononucleosis syndromes. West J Med 1977;126:445-459.

[39] Yadav SK, Saigal S, Choudhary NS, Saha S, Kumar N, Soin AS. Cytomegalovirus Infection in liver transplant recipients: current approach to diagnosis and management. J Clin Exp Hepatol 2017;7:144-151. doi:10.1016/j. jceh.2017.05.011.

[40] Sacks SL, Freeman HJ. Cytomegalovirus hepatitis: evidence for direct hepatic viral infection using monoclonal antibodies. Gastroenterology hepatic viral infection using monoclonal antibodies.
1984;86:346-350. doi:10.1016/0016-5085(84)90421-9.

[41] Reller LB. Granulomatous hepatitis associated with acute cytomegalovirus infection. Lancet 1973;1:20-22. doi:10.1016/S0140-6736(73)91226-9.

[42] Miguelez M, Gonzalez A, Perez F. Severe cytomegalovirus hepatitis in a pregnant woman treated with ganciclovir. Scand J Infect Dis 1998;30:304305. doi: $10.1080 / 00365549850160981$

[43] Bonkowsky HL, Lee RV, Klatskin G. Acute granulomatous hepatitis. Occurrence in cytomegalovirus mononucleosis. JAMA 1975;233:1284-1288. doi: 10.1001 jama.1975.03260120046019.

[44] Ten Napel $\mathrm{CH}$, Houthoff HJ, The TH. Cytomegalovirus hepatitis in normal and immune compromised hosts. Liver 1984;4:184-194. doi:10.1111/ j.1600-0676.1984.tb00926.x

[45] Shusterman NH, Frauenhoffer C, Kinsey MD. Fatal massive hepatic necrosis in cytomegalovirus mononucleosis. Ann Intern Med 1978;88:810-812. doi:10.7326/0003-4819-88-6-810.

[46] Puccia F, Lombardo V, Giannitrapani L, Licata A, Mazzola G, Soresi M. Case report: acute portal vein thrombosis associated with acute cytomegalovirus infection in an immunocompetent adult. J Ultrasound 2017;20:161rus infection in an immunocompetent

[47] Chan A, Bazerbachi F, Hanson B, Alraies MC, Duran-Nelson A. Cytomegalovirus hepatitis and pancreatitis in the immunocompetent. Ochsner J 2014;14:295-299.

[48] Ladd AM, Goyal R, Rosainz L, Baiocco P, DiFabrizio L. Pulmonary embolism and portal vein thrombosis in an immunocompetent adolescent with acute cytomegalovirus hepatitis. J Thromb Thrombolysis 2009;28:496-499. doi:10.1007/s11239-008-0303-1.

[49] Qian JY, Bai XY, Feng YL, Zhu WJ, Yao F, Li JN, et al. Cholestasis, ascites and pancytopenia in an immunocompetent adult with severe cytomegalovirus hepatitis. World J Gastroenterol 2015;21:12505-12509. doi:10.3748/wjg. v21.i43.12505.

[50] Hooi WF, Malhotra A, Pollard J. Cytomegalovirus associated longitudinally extensive transverse myelitis and acute hepatitis in an immunocompetent adult. J Clin Neurosci 2018;50:152-154. doi:10.1016/j.jocn.2018.01.041.

[51] Ates İ, Kaplan M, Yilmaz N, Çiftçi F. Epstein-Barr Virus and Cytomegalovirus induced Acute Hepatitis in Young Female Patient. Euroasian J Hepatogastroenterol 2015;5:60-61. doi:10.5005/jp-journals-10018-1134.

[52] Clarke J, Craig RM, Saffro R, Murphy P, Yokoo H. Cytomegalovirus granulomatous hepatitis. Am J Med 1979;66:264-269. doi:10.1016/00029343(79)90543-6.

[53] Gróza S. Cytomegalovirus hepatitis (diagnosis and differential diagnosis). Acta Hepatogastroenterol (Stuttg) 1977;24:340-343.

[54] Gupta P, Suryadevara M, Das A. Cytomegalovirus-induced hepatitis in an immunocompetent patient. Am J Case Rep 2014;15:447-449. doi:10.12659/ AJCR.890945.

[55] Jensen KO, Angst E, Hetzer FH, Gingert C. Acute cytomegalovirus hepatitis in an immunocompetent host as a reason for upper right abdominal pain. Case Rep Gastroenterol 2016;10:36-43, doi:10.1159/000442972.

[56] Ma Y, Feng J, Qi Y, Dou XG. An immunocompetent adult patient with hepatitis and guillain-barré syndrome after cytomegalovirus infection. Virol J 2011;8:95. doi:10.1186/1743-422X-8-95.

[57] Oku T, Maeda M, Waga E, Wada Y, Nagamachi Y, Fujita M, et al. Cytomegalovirus cholangitis and pancreatitis in an immunocompetent patient. J Gastroenterol 2005; 40:987-992. doi:10.1007/s00535-005-1683-z.

[58] Toghill PJ, Bailey ME, Williams R, Zeegen R, Bown R. Cytomegalovirus hepatitis in the adult. Lancet 1967;1:1351-1354. doi:10.1016/s0140-6736(67) 91762-x.

[59] Tzavella K, Zantidis A, Economou I, Mandraveli K, Alexiou-Daniel S, Dimitriadis A, et al. Portal hypertension caused by acute cytomegalovirus infection with liver involvement in an immunocompetent patient. Scand J Infect Dis 2007;39:177-178. doi:10.1080/00365540600794410.

[60] Zubiaurre L, Zapata E, Bujanda L, Castillo M, Oyarzabal I, Gutiérrez-Stampa MA, et al. Cytomegalovirus hepatitis and myopericarditis. World J Gastroenterol 2007;13:647-648. doi:10.3748/wjg.v13.i4.647. 
[61] Serna-Higuera C, González-García M, Milicua JM, Muñoz V. Acute cholestatic hepatitis by cytomegalovirus in an immunocompetent patient resolved with ganciclovir. J Clin Gastroenterol 1999;29:276-277. doi:10.1097/ 00004836-199910000-00010.

[62] Fernández-Ruiz M, Muñoz-Codoceo $C$, López-Medrano F, Faré-García $R$, Carbonell-Porras A, Garfia-Castillo C, et al. Cytomegalovirus myopericarditis and hepatitis in an immunocompetent adult: successful treatment with oral valganciclovir. Intern Med 2008;47:1963-1966. doi:10.2169/internalmedicine.47.1480.

[63] Mizuta M, Schuster MG. Cytomegalovirus hepatitis associated with use of anti-tumor necrosis factor-alpha antibody. Clin Infect Dis 2005;40:10711072. doi:10.1086/428672.

[64] Razonable RR. Cytomegalovirus infection after liver transplantation: current concepts and challenges. World J Gastroenterol 2008;14:4849-4860. doi:10.3748/wjg.14.4849.

[65] Stratta RJ, Shaefer MS, Markin RS, Wood RP, Kennedy EM, Langnas AN, et al. Clinical patterns of cytomegalovirus disease after liver transplantation. Arch Surg 1989;124:1443-1449. discussion 1449-1450doi:10.1001/ tion. Arch Surg 1989;124:1443-1448
archsurg.1989.01410120093018.

[66] Herman D, Han H. Cytomegalovirus in liver transplant recipients. Curr Opin Organ Transplant 2017;22:345-350. doi:10.1097/MOT.00000000000 00433.

[67] Pastacaldi S, Teixeira R, Montalto P, Rolles K, Burroughs AK. Hepatic artery thrombosis after orthotopic liver transplantation: a review of nonsurgical causes. Liver Transpl 2001;7:75-81. doi:10.1053/jlts.2001.22040.

[68] Reddy V, Meier-Kriesche HU, Greene S, Schold JD, Wingard JR. Increased levels of tumor necrosis factor alpha are associated with an increased risk of cytomegalovirus infection after allogeneic hematopoietic stem cell transplantation. Biol Blood Marrow Transplant 2005;11:698-705. doi:10.1016/j. plantation. Biol Blood

[69] Baillie J, Sahlender DA, Sinclair JH. Human cytomegalovirus infection inhibits tumor necrosis factor alpha (TNF-alpha) signaling by targeting the 55-kilodalton TNF-alpha receptor. J Virol 2003;77:7007-7016. doi:10.1128/ jvi.77.12.7007-7016.2003

[70] Popkin DL, Virgin HW4th. Murine cytomegalovirus infection inhibits tumor necrosis factor alpha responses in primary macrophages. J Virol 2003;77: 10125-10130. doi:10.1128/jvi.77.18.10125-10130.2003.

[71] Toghill PJ, Williams R, Stern H. Cytomegalovirus infection in chronic liver disease. Gastroenterology 1969;56:936-937.

[72] Lautenschlager I, Höckerstedt K, Jalanko H, Loginov R, Salmela K, Taskinen $\mathrm{E}$, et al. Persistent cytomegalovirus in liver allografts with chronic rejection. Hepatology 1997;25:190-194. doi:10.1053/jhep.1997.v25.pm00089852 89.

[73] Arnold JC, Portmann BC, O'Grady JG, Naoumov NV, Alexander G], Williams R. Cytomegalovirus infection persists in the liver graft in the vanishing bile duct syndrome. Hepatology 1992;16:285-292. doi:10.1002/ hep.1840160202.

[74] Faivre M, Cottet V, Bour JB, Richou C, Valmary-Degano S, Thiefin G, et al. Impact of cytomegalovirus infection on the outcome of patients with cirrhosis: A preliminary study. J Clin Gastroenterol 2019;53:236-241. doi:10.1097/ MCG.0000000000001039.

[75] Kotton CN, Kumar D, Caliendo AM, Huprikar S, Chou S, Danziger-Isakov $L$, et al. The third international consensus guidelines on the management of cytomegalovirus in solid-organ transplantation. Transplantation 2018; 102:900-931. doi:10.1097/TP.0000000000002191.

[76] Humar A, Mazzulli T, Moussa G, Razonable RR, Paya CV, Pescovitz MD, et al. Clinical utility of cytomegalovirus (CMV) serology testing in high-risk CMV D+/ R- transplant recipients. Am J Transplant 2005;5:1065-1070. doi:10.1111/ j.1600-6143.2005.00797.x.

[77] Gorensek MJ, Carey WD, Vogt D, Goormastic M. A multivariate analysis of risk factors for cytomegalovirus infection in liver-transplant recipients. Gastroenterology 1990;98:1326-1332. doi:10.1016/0016-5085(90)90352-2.

[78] Ross SA, Novak Z, Pati S, Boppana SB. Overview of the diagnosis of cytomegalovirus infection. Infect Disord Drug Targets 2011;11:466-474. doi: $10.2174 / 187152611797636703$.

[79] Lautenschlager I, Halme L, Höckerstedt K, Krogerus L, Taskinen E. Cytomegalovirus infection of the liver transplant: virological, histological, immunological, and clinical observations. Transpl Infect Dis 2006;8:21-30. doi:10.1111/j.1399-3062.2006.00122.x

[80] Revello MG, Zavattoni M, Baldanti F, Sarasini A, Paolucci S, Gerna G. Diagnostic and prognostic value of human cytomegalovirus load and IgM antibody in blood of congenitally infected newborns. J Clin Virol 1999;14:5766. doi:10.1016/s1386-6532(99)00016-5.

[81] Ohyama S, Fujioka K, Fukushima S, Abe S, Ashina M, Ikuta T, et al. Diagnostic value of cytomegalovirus igm antibodies at birth in PCR-conagnostic value of cytomegalovirus igm antibodies at birth in PCR-con-
firmed congenital cytomegalovirus infection. Int J Mol Sci 2019;20:3239. firmed congenital cytomegalov

[82] Genser B, Truschnig-Wilders M, Stünzner D, Landini MP, Halwachs-Baumann G. Evaluation of five commercial enzyme immunoassays for the de- tection of human cytomegalovirus-specific IgM antibodies in the absence of a commercially available gold standard. Clin Chem Lab Med 2001;39:6270. doi:10.1515/CCLM.2001.014

[83] Kotton CN, Kumar D, Caliendo AM, Asberg A, Chou S, Danziger-Isakov L, et al. Updated international consensus guidelines on the management of cytomegalovirus in solid-organ transplantation. Transplantation 2013;96: 333-360. doi:10.1097/TP.0b013e31829df29d.

[84] Greanya ED, Partovi N, Yoshida EM, Shapiro RJ, Levy RD, Sherlock CH, et $\mathrm{al}$. The role of the cytomegalovirus antigenemia assay in the detection and prevention of cytomegalovirus syndrome and disease in solid organ transplant recipients: A review of the British Columbia experience. Can J Infect Dis Med Microbiol 2005;16:335-341. doi:10.1155/2005/679386.

[85] Brand RE, Hinriahs SH, Zetterman RK. The clinical utility of viral assays in the diagnosis of cytomegalovirus (CMV) hepatitis. Gastroenterology 1995; 108:A6. doi:10.1016/0016-5085(95)22689-3.

[86] Piiparinen H, Höckerstedt K, Grönhagen-Riska C, Lautenschlager I. Comparison of two quantitative CMV PCR tests, Cobas Amplicor CMV Monitor and TaqMan assay, and pp65-antigenemia assay in the determination of and TaqMan assay, and pp65-antigenemia assay in the determination of 2004;30:258-266. doi:10.1016/j.jcv.2003.12.010.

[87] Gleaves CA, Smith TF, Shuster EA, Pearson GR. Comparison of standard tube and shell vial cell culture techniques for the detection of cytomegalovirus in clinical specimens. J Clin Microbiol 1985;21:217-221. doi:10.1128/ JCM.21.2.217-221.1985.

[88] Seehofer D, Meisel H, Rayes N, Stein A, Langrehr JM, Settmacher U, et al. Prospective evaluation of the clinical utility of different methods for the detection of human cytomegalovirus disease after liver transplantation. Am J Transplant 2004;4:1331-1337. doi:10.1111/j.1600-6143.2004.00510.x.

[89] Caliendo AM, St George K, Kao SY, Allega J, Tan BH, LaFontaine R, et al. Comparison of quantitative cytomegalovirus (CMV) PCR in plasma and CMV antigenemia assay: clinical utility of the prototype AMPLICOR CMV MONITOR test in transplant recipients. J Clin Microbiol 2000;38:2122-2127. doi: $10.1128 /$ JCM.38.6.2122-2127.2000

[90] Wolf DG, Spector SA. Early diagnosis of human cytomegalovirus disease in transplant recipients by DNA amplification in plasma. Transplantation 1993:56:330-334 doi:10.1097/00007890-199308000-00014.

[91] Mhiri L, Kaabi B, Houimel M, Arrouji Z, Slim A. Comparison of pp65 antigenemia, quantitative PCR and DNA hybrid capture for detection of cytomegalovirus in transplant recipients and AIDS patients. J Virol Methods 2007;143:23-28. doi:10.1016/j.jviromet.2007.01.033.

[92] Sanghavi SK, Abu-Elmagd K, Keightley MC, St George K, Lewandowski $\mathrm{K}$, Boes SS, et al. Relationship of cytomegalovirus load assessed by realtime PCR to pp65 antigenemia in organ transplant recipients. J Clin Virol 2008;42:335-342. doi:10.1016/j.jcv.2008.03.031.

[93] Snover DC, Horwitz CA. Liver disease in cytomegalovirus mononucleosis: a light microscopical and immunoperoxidase study of six cases. Hepatology 1984;4:408-412. doi:10.1002/hep.1840040309.

[94] Drebber U, Kasper HU, Kern MA, Sattler S, Odenthal M, Dienes HP. Comparison of the lymphocytic infiltrate in Epstein-Barr Virus (EBV) and Cytomegalovirus (CMV) induced hepatitis. Pathology - Research and Practice 2004;200:307. doi:10.1016/s0344-0338(04)80601-0.

[95] Paya C, Humar A, Dominguez E, Washburn K, Blumberg E, Alexander B, et al. Efficacy and safety of valganciclovir vs. oral ganciclovir for prevention of cytomegalovirus disease in solid organ transplant recipients. Am J Transplant 2004;4:611-620. doi:10.1111/j.1600-6143.2004.00382.x.

[96] Mumtaz K, Faisal N, Husain S, Morillo A, Renner EL, Shah PS. Universal prophylaxis or preemptive strategy for cytomegalovirus disease after liver transplantation: a systematic review and meta-analysis. Am J Transplant 2015;15:472-481. doi:10.1111/ajt.13044.

[97] Singh N, Winston DJ, Razonable RR, Lyon GM, Silveira FP, Wagener MM, et al. Effect of preemptive therapy vs antiviral prophylaxis on cytomegalovirus disease in seronegative liver transplant recipients with seropositive donors: A randomized clinical trial. JAMA 2020;323:1378-1387. doi:10.1001/ jama.2020.3138.

[98] Bodro M, Sabé N, Lladó L, Baliellas C, Niubó J, Castellote J, et al. Prophylaxis versus preemptive therapy for cytomegalovirus disease in high-risk
liver transplant recipients. Liver Transpl 2012;18:1093-1099. doi:10.1002/ liver transpla

[99] Weigand K, Schnitzler P, Schmidt J, Chahoud F, Gotthardt D, Schemmer P, et al. Cytomegalovirus infection after liver transplantation incidence, risks, and benefits of prophylaxis. Transplant Proc 2010;42:2634-2641. doi:10.1016/ j.transproceed.2010.04.025.

[100] Shmueli E, Or R, Shapira MY, Resnick IB, Caplan O, Bdolah-Abram T, et al. High rate of cytomegalovirus drug resistance among patients receiving preemptive antiviral treatment after haploidentical stem cell transplantation. J Infect Dis 2014;209:557-561. doi:10.1093/infdis/jit475.

[101] Chou S. Approach to drug-resistant cytomegalovirus in transplant recipients. Curr Opin Infect Dis 2015;28:293-299. doi:10.1097/QCO.00000000 00000170 . 